\title{
Comprehensive assessment of a flora and a productivity of green planting in the city of Abakan
}

\author{
Elena Yu. Zhukova*, Elena G. Lagunova \\ Khakas State University, 655000 Abakan, the Russian Federation
}

\begin{abstract}
The article provides information about the level of species diversity, biological and ecological composition, the dynamic of the vegetation productivity of a green planting in the city of Abakan (the steppe zone). The inventory of the flora revealed 288 species of higher vascular plants from 59 families and 183 genera. The basis of flora is the angiosperms, including 57 families (96.6\%), 179 genera $(97.8 \%), 282$ species $(97.9 \%)$. The leading positions belong to the families Asteraceae (11.8\%), Poaceae and Rosaceae (10.8 \%), Fabaceae (7.3\%). The most important genera in the flora were boreal ones - Carex, Artemisia (2.8 $\%)$, Potentilla $(1.7 \%)$. The ecological analysis showed the predominance of mesophytes $(45.5 \%)$. Perennial plants with clustered fleshy roots and shortrhizomatous ones $(21.5 \%)$ were a main biomorph. The analysis of the primary production of urban vegetation according to Terra MODIS data from 2000 to 2018 was carried out. The highest seasonal growth rates observed in 2001 and 2007, and the lowest ones were in 2004 and 2008. The average annual growth rates were $115 \pm 9 \%$ for May, $107 \pm 5 \%$ for June, $107 \pm 5 \%$ for July, $119 \pm 14 \%$ for July, and $120 \pm 11 \%$ for August. The positive trend in the productivity of urban vegetation was established using the series criteria.
\end{abstract}

The city of Abakan (Khakasia) is located in the central part of the Minusinsk Basin (Uybat steppe) and covers an area of $112.87 \mathrm{~km}^{2}$. The city is located in an area with frequent inversions, which makes it difficult to disperse pollutants. The main types of green spaces in the city are parks, squares, street plantations and public lands, which occupy a third of the area. The collection of higher vascular plants was carried out by route method from May to early September from 2012 to 2017 to cover the periods of the flowering of different systematic groups. In the laboratory, the binary name of the collected plants was determined by the Flora of Siberia T. 1 - 14 (1987 - 2003) [1].

The source satellite data represented a common 8-day composite of growth primary production (GPP) [2]. For retrieving Terra MODIS data we used the site https://lpdaacsvc.cr.usgs.gov/appeears. In the paper a discrete one-dimensional time series for equidistant 8-day moments was considered. To characterize the series, we used the growth rate - the ratio of the subsequent level to the previous one (\%).

Several factors influence the formation of time series values:

$$
x(t)=T(t)+S(t)+C(t)+N(t), t=\overline{1, P},
$$

\footnotetext{
* Corresponding author: biosara@mail.ru
} 
where $\mathrm{T}(\mathrm{t})$ - trend component; $\mathrm{S}(\mathrm{t})$ - seasonal component; $\mathrm{C}(\mathrm{t})$ - cyclic and $\mathrm{N}(\mathrm{t})$ - irregular components [3].

The presence or absence of a nonrandom (and time-dependent $t$ ) component in the decomposition of time series (1) was determined according to the series criterion based on the median [3]. The value of the series is compared with the sample median, and if $x(t)>$, then for the corresponding observation, the member of the sequence forming the series takes the sign "+", if $\mathrm{x}(\mathrm{t})<$, then the sign "-". The hypothesis of a randomness of a series is not rejected, if the inequalities are carried out (for $5 \%$ level of a significance): (2)

$$
\begin{aligned}
& \tau_{\max }(n)<[1.43 \ln (n+1)] \\
& v(n)>\left[\frac{1}{2}(n+2-1.96 \sqrt{n-1}],\right.
\end{aligned}
$$

where $n$ - the length of the time series; $v(n)$ - the number of series; $\tau$ max $(n)-$ the number of consecutive pluses or minuses in the longest series.

The module «Time Series/Forecasting» of the program «Statistica» was used to perform time series decomposition according to Census 1 method.

There were 288 species of higher vascular plants belonging to 59 families and 183 genera in the flora of parks and squares of Abakan. The basis of flora were angiosperms, including 57 families, which were (96.6\%), 179 genera (97.8\%), 282 species $(97.9 \%)$. Vascular cryptogamous plants comprised the Equisetaceae family (1.7\%), Equisetum genus $(0.6 \%)$ and 2 species $(0.7 \%)$ : Equisetum arvense and E. pratense. The composition of gymnospermous plants included Pinaceae family (1.7\%), 3 genera - Larix, Picea, Pinus $(1.6 \%)$ and 4 species (1.4\%): Larix sibirica Ledeb., Picea obovata Ledeb., Picea pungens Engelm., Pinus sylvestris L.

Ten leading families comprise $62.2 \%$ of the species of the flora of the parks and gardens of the city of Abakan. The leading positions belong to the largest families of Asteraceae (34 species, $11.8 \%$ of the total number of species), Poaceae and Rosaceae (31 species or $10.8 \%$ ). Asteraceae and Poaceae families are the most common in the flora of Khakasia. The high position of Rosaceae in the spectrum was explained by the presence of numerous tree-shrubed adventive species (13 species) used in the greening. In the Rosaceae family Pyrus ussuriensis Maxim., Rosa majalis Herrm.,Padus avium Mill., Spiraea chamaedryfolia L., Sorbus sibirica Hedl., Sorbaria sorbifolia (L.) A. Braun, Potentilla anserina, Geum aleppicum Jacq. are the most common species. Representatives of the Fabaceae family (21 species, $7.3 \%$ ) are characterized by high adaptation to urbanization (Trifolium pratense L., Amoria repens (L.) C. Presl, Medicago sativa L., Onobrychis arenaria (Kit.) DC., Vicia cracca L.).

Among ten most common families are Brassicaceae (5.5\%), Ranunculaceae (3.8\%), Lamiaceae (3.5\%), Cyperaceae (3.1\%), Boraginaceae и Caryophyllaceae (2.8 \%). Groups of plants with different attitudes to soil moisture were identified for the ecological analysis [4]. Most of the flora consists of mesophytes (131 species, $45.5 \%$ ). It is normal, since there are enough habitats with favorable water regime (meadows, drainage channels banks, etc.). A group of mesoxerophytes (75 species or $26.0 \%$ ), growing along roads, paths, steppe meadows, on the outskirts of green zones, was the second. Less significant was the group of xerophytes, which has 39 species (13.5\%). There are some of hygrophytes in the city (22 species or $7.6 \%$ of the total number of species). Mesohygrophytes (17 species or $6.0 \%$ ) and hydrophytes (4 species, 1.4\%) were less common. Favorable conditions for the growth of hydrophytes are created in the coastal zone of numerous water sources.

It is possible to characterize habitat conditions based on the analysis of plant life forms according to I. G. Serebryakov (1962) [5]. The main biomorphological group is the group of perennial herbaceous plants (165 species, or $57.3 \%$ of the total number of species). The most numerous were perennials with clustered fleshy roots and short-rhizome ones, 
including 62 species $(21.5 \%)$. The long-rhizomatous plants are represented by 44 species $(15.3 \%)$. The composition of rod-rooted plants growing in steppe areas and steppe meadows, along the roadsides and in the areas of buildings included 31 species $(10.8 \%)$. Loose-bunchgrass (15 species, $5.2 \%$ ) and dense-bunchgrass ( 9 species, 3.1\%) belonged mainly to the Poaceae family. Bulbous plants were presented by four species $(1.4 \%)$ of Alliaceae (Allium anisopodium Ledeb., A. ramosum L. etc) and Lilliaceae (Gagea fedtschenkoana Pasch., Tulipa heteropetata Ledeb., T. uniflora (L.) Besserex Backer) families. There were many annual herbaceous plants (45 species, 15.6\%) in the city. Many of them are weed species, which is associated with a strong anthropogenic factor. Biennials are represented by 25 species, or make up $8.7 \%$ of the total number of species. A significant part of shrubs (30 species, $10.4 \%$ ) belongs to Rosaceae family: Sorbaria sorbifolia, Padus avium, Spiraea media Schmidt etc. Among the trees (20 species, $7.0 \%$ ), Ulmus pumila L., Betula pendula Roth, species from the genus Populus, and species of the family Pinaceae are common. There are 2 species (1.6\%) of dwarf subshrubs (Artemisia frigida Willd. and Potentilla bifurca L.), and 1 species of subshrubs (Solanum kitagawae Schonb.-Tem.). Perennial plants are more adapted to the inclement conditions than annual and biennial plants.

According to data from the Terra MODIS primary production, the growth rates for the time series from 2000 to 2018 were calculated (Fig. 1).

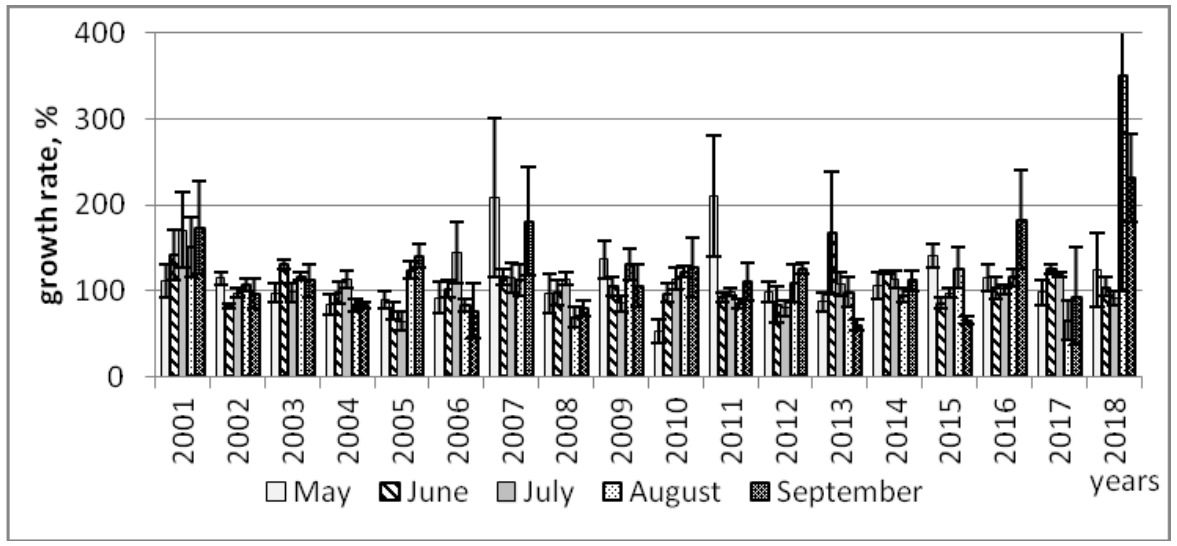

Fig. 1. Growth rates of the primary growth production of vegetation (Abakan, 2001-2018)

As can be seen in Figure 1, the maximum growth rates were noted in 2001 and 2007. Minimum values were found in 2004 and 2008. Intensive growth rates were observed not only in May (2007, 2009, 2011), but also in August (2001, 2005, 2007, 2012, 2016, 2018). It is typical of the steppe zone (the second peak of the growing season). Absolute maximum of growth rates for the entire period (350\%) was recorded in 2018. It is associated with favorable weather conditions and the appearance of new green zones, planting of new rapidly growing trees and lawns. To establish the presence of a trend, the values $(n=398, v$ (n) $=45, \tau \max =14$ ) were substituted into the system (2). Both inequalities violated; therefore, hypothesis (2) rejected, i.e. in the original time series there was a non-random component. Since the components of the series depend on the level of productivity of the season, a multiplicative model of interaction was chosen.

As a result of seasonal decomposition, components involved in the formation of a time series using the Census 1 method (Fig. 2-3) are highlighted. The dynamics of the vegetation productivity of the city of Abakan indicated typical seasonal fluctuations overlapping the trend. The indicator was in the range of $90-115 \%$. The growth rate is determined by the phenology of woody deciduous vegetation in the arid zone. 


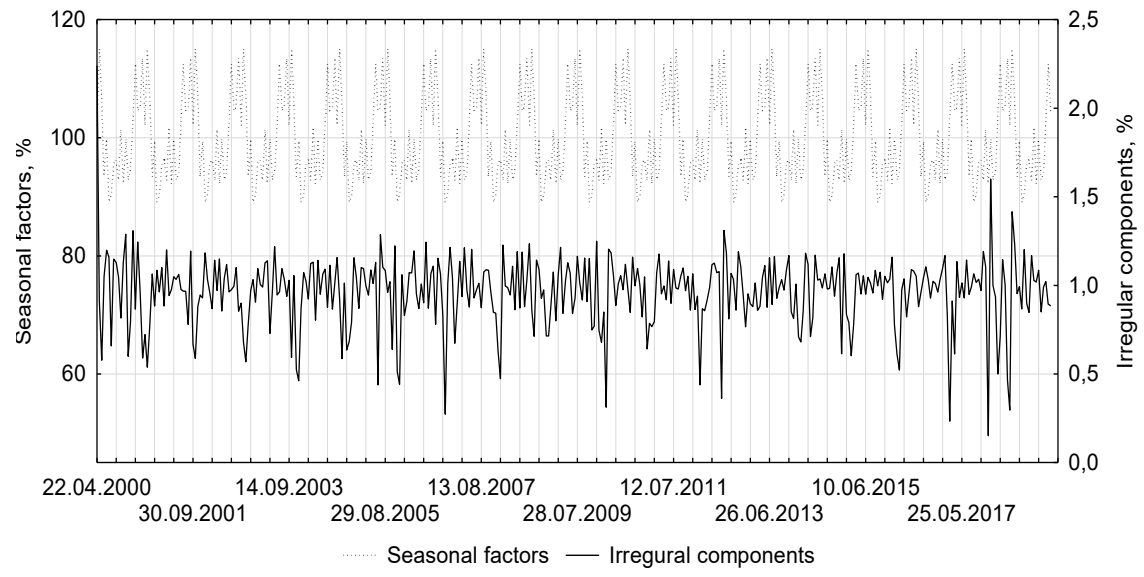

Fig. 2. Seasonal and irregular components of the primary production (Abakan, 2001-2018)

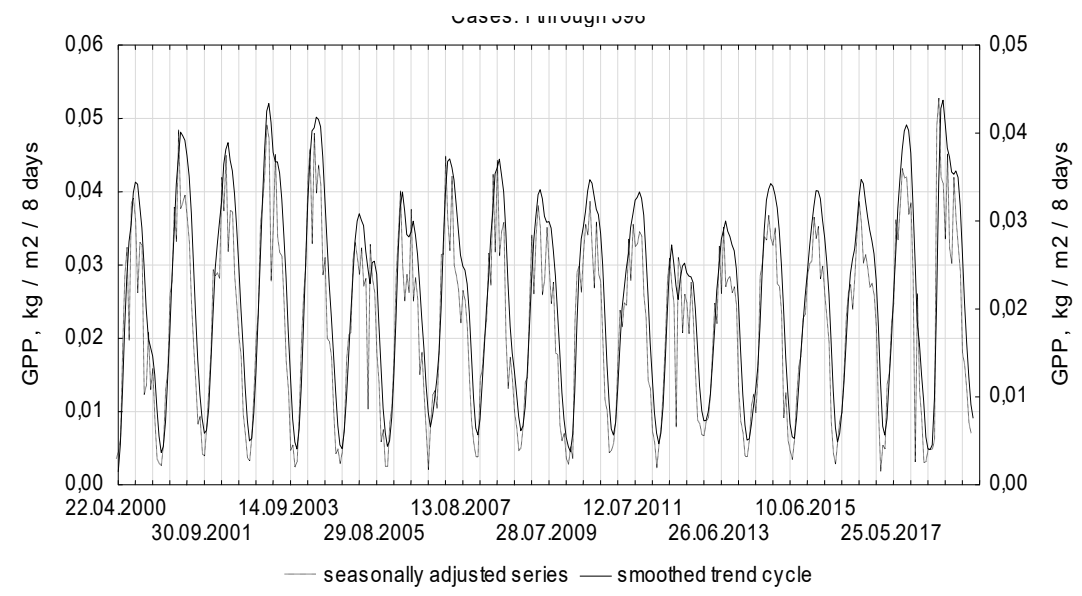

Fig. 3. Trend cycle of the primary production (Abakan, 2001-2018)

The contribution of the irregular component (change in the area of the green zones, pollution, damage) amounted to an average of about $1.00 \%$ (in the range of $0.02-1.50 \%$ ), mainly a decrease in performance.

After seasonal adjustment of the series, one and less often two peaks in the development of vegetation were found (Fig. 3). The trend cycle showed maximum values $\left(\geq 0.04 \mathrm{~kg} / \mathrm{m}^{2}\right.$ / 8 days) of the growth productivity indicator in 2001-2004 and in 2017-2018. Minimum values ( $\leq 0.03 \mathrm{~kg} / \mathrm{m}^{2} / 8$ days) were noted for 2005 and 2012. These periods coincided with severe drought. Satellite indicators of productivity correlated with the sum of positive temperatures $\left(\mathrm{R}^{2}=0.603\right)$ and the hydrothermal coefficient $\left(\mathrm{R}^{2}=0.727\right)$ in the study area.

The trend were on average $0.01 \mathrm{~kg} / \mathrm{m}^{2} / 8$ days lower, compared to the seasonally adjusted graph. In a time series of traced wave-like cycle, the length of which 5-6 years and the positive trend were observed in 2017-2018.

\section{Acknowledgments}

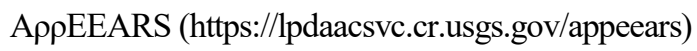




\section{References}

1. Flora of Siberia: in 14 volumes / edited by L.I. Malyshev (Novosibirsk, Nauka, 1987-2003)

2. S. Running, Q. Mu, M. Zhao, MOD17A2H (2015).

3. S.A. Aivazyan, Fundamentals of econometrics (YUNITI-DANA, 2001)

4. T.K. Goryshina, The Ecology of plants (Higher school, 1979)

5. I.G. Serebryakov, Ecological morphology of plants. Life forms of angiosperms and conifers (Higher school, 1962) 